American Journal of Infectious Diseases 7 (3): 75-79, 2011

ISSN 1553-6203

(C) 2011 Science Publications

\title{
Monitoring Levothyroxine Dose during Pregnancy: A Prospective Study
}

\author{
${ }^{1}$ Juhi Agarwal, ${ }^{1}$ Sirimavo Nair and ${ }^{2}$ Tarun Sekhri \\ ${ }^{1}$ Department of Foods and Nutrition, \\ Faculty of Family and Community Sciences, \\ M.S. University of Baroda, Vadodara, 390 002, Gujarat, India \\ ${ }^{2}$ Division of Endocrinology and Thyroid Research, \\ Institute of Nuclear Medicine and Allied Sciences, \\ Brig. S.K. Mazumdar Marg, Delhi, 110 054, India
}

\begin{abstract}
Problem statement: Thyroid dysfunction in pregnant women can influence the outcome for mother and fetus at all stages of pregnancy. As the fetus is entirely dependent on maternal thyroid hormones for its development until about 13 weeks of gestation, it is important to ensure adequate thyroxine substitution in pregnant women during the first trimester. The aim of this prospective study was to explore whether hypothyroidic pregnant women are adequately levothyroxine $\left(\mathrm{L}-\mathrm{T}_{4}\right)$ substituted in early pregnancy. Approach: During March 2008 to July 2009, 93 pregnant females with thyroid diseases were followed at the outpatient department of INMAS. At the first visit 86 patients were on L-T $\mathrm{T}_{4}$ substitution for hypothyroidism. Seven other patients had hyperthyroidism. The patients were regularly followed every 4-8 weeks during pregnancy for dose adjustment. Before each visit serum Free Thyroxine ( $\left.\mathrm{FT}_{4}\right)$ and TSH concentrations were determined. Results: Of the 86 patients on thyroxine substitution for hypothyroidism $56(65.12 \%)$ had serum TSH values within the reference range at their first TSH test. Thirty (34.9\%) had TSH values outside the reference range. In 5 patients TSH was $<0.27 \mu \mathrm{IU} \mathrm{mL} \mathrm{m}^{-1}$. Fifty $(58.13 \%)$ of the patients had to increase their thyroxine dose during pregnancy. The initial L- $\mathrm{T}_{4}$ increase at the first evaluation during pregnancy was $17.46 \pm 30.8 \mu \mathrm{g} \mathrm{day}^{-1}$. In the 50 patients who needed to increase $\mathrm{L}_{-} \mathrm{T}_{4}, 26 \%$ reached a definitive therapeutic dosage within 12th week of pregnancy, $24 \%$ within the 20th week and $50 \%$ within the 31 st week. Conclusion/Recommendations: In $34.9 \%$ of pregnant women on $\mathrm{L}-\mathrm{T}_{4}$ substitution for hypothyroidism, serum TSH values were abnormal when first tested and they had increased chances of fetal loss if not treated timely. Thyroid function in pregnant women on thyroxine substitution should be monitored as soon as pregnancy has been confirmed and carefully followed during pregnancy.
\end{abstract}

Key words: Thyroid, levothyroxine, pregnancy, hypothyroidism

\section{INTRODUCTION}

Primary hypothyroidism is a common disorder in women of childbearing age, with an estimated prevalence of $2-3 \%$ of women during pregnancy (Abalovich et al., 2007). An estimated 1-2\% of all pregnant women receive levothyroxine $\left(\mathrm{L}-\mathrm{T}_{4}\right)$ therapy for hypothyroidism when identified clinically. Epidemiologic studies indicate that $0.4 \%$ of pregnant women have serum thyrotropin concentrations above 10 $\mu \mathrm{U}$ per milliliter at 15-18 weeks of gestation from either under-replacement of $\mathrm{L}-\mathrm{T}_{4}$ therapy or undiscovered primary hypothyroidism (Allan et al., 2000).

Adequate maternal thyroid function during pregnancy is critical to the mother and developing fetus. The issue of suboptimal maternal thyroid function is especially crucial during the first 12-14 weeks of gestation; when the fetal brain development is entirely reliant on placental transfer of maternal thyroid hormone (Casey et al., 2005).

Overtly hypothyroidic women carry an increased risk of both early and late obstetrical complications, such as spontaneous abortion, gestational hypertension, placental abruption and postpartum haemorrhage (Leung et al., 1993; Davis et al., 1988). Untreated maternal hypothyroidism is also associated with adverse neonatal outcomes, including low birth weight and increased risk of perinatal death (Davis et al., 1988). Even subclinical hypothyroidism in pregnancy is

Corresponding Author: Juhi Agarwal, Department of Foods and Nutrition, Faculty of Family and Community Sciences, M.S. University of Baroda, Vadodara-390 002, Gujarat, India 
associated with a doubling of the rate of preterm delivery (Casey et al., 2005).

Children born to overtly hypothyroid mothers have shown an impairment in neuropsychological developmental indices, IQ scores and school learning abilities (Abalovich et al., 2007). Even subtle deficiencies in maternal thyroid hormone levels have been shown to adversely affect cognition, intellect and motor development in offspring (Burrow et al., 1994; Pop et al., 2003).

Current literature indicates that $50-85 \%$ of women with hypothyroidism who are being treated with $\mathrm{L}-\mathrm{T}_{4}$ require an increase in their dose of this hormone after they become pregnant (Abalovich et al., 2002; Alexander et al., 2004). Unfortunately, between 24 and $43 \%$ of women with hypothyroidism who are taking $\mathrm{L}^{-\mathrm{T}_{4}}$ before pregnancy have elevated serum Thyroid Stimulating Hormone (TSH) concentrations at their first prenatal visit after becoming pregnant (Idris et al., 2005).

It is known that the pregnant women is the sole source of fetal supply of thyroid hormones from conception to approximately 13 weeks of gestation when thyroid function has developed, so adequate thyroxine substitution in pregnant women during the first trimester should be ensured.

The aim of this prospective study was to explore whether hypothyroidic pregnant women are adequately levothyroxine $\left(\mathrm{L}-\mathrm{T}_{4}\right)$ substituted in early pregnancy.

\section{MATERIALS AND METHODS}

Subjects: Women with primary hypothyroidism who desired pregnancy were recruited from out-patient department of Institute of Nuclear Medicine and Allied Sciences (INMAS), Delhi which is a tertiary referral centre. In the period between March 2008 to July 2009, 93 pregnant women were enrolled. Among them, eighty six were hypothyroidic and already on $\mathrm{L}_{-} \mathrm{T}_{4}$ before conception. All hypothyroid women followed up in the centre were invited to come to our out-patient department with new thyroid function tests as soon as pregnancy was ascertained for adjustment of $\mathrm{L}-\mathrm{T}_{4}$ therapy. The increment of ${\mathrm{L}-\mathrm{T}_{4}}_{4}$ dose at the first evaluation during pregnancy was based on TSH value. All pregnant women were monitored every 4-6 weeks and L$\mathrm{T}_{4}$ dose was modified to maintain the serum TSH within the reference range. The women who modified $\mathrm{L}_{-} \mathrm{T}_{4}$ dosage were rechecked for TSH levels after 4 weeks to insure the achievement of the therapeutic target.

The Institutional Ethics Committee at INMAS approved the study protocol and the subjects were recruited after prior informed written consent.
Hormone assays: Free Thyroxine $\left(\mathrm{FT}_{4}\right)$ and TSH were estimated by Electrochemiluminescence (ECL) technique using commercially available kits from Roche Diagnostics with Elecsys 1010 analyzer, normal range being $12-22 \mathrm{pmol} / \mathrm{L}$ and $0.27-4.2 \mu \mathrm{IU} / \mathrm{mL}$, respectively.

The analytical sensitivity and total precision values for $\mathrm{FT}_{4}$ and TSH assays were $0.3 \mathrm{pM} / \mathrm{L}$ and $2.7 \%$ and $0.005 \mu \mathrm{IU} / \mathrm{mL}$ and $2.2 \%$, respectively. The intra assay Coefficients of Variation (CV) for the assays were 1.4 and $1.9 \%$, respectively.

Statistical analysis: Statistical analysis was performed using one way ANOVA, followed by Bonferroni's and Dunn's post hoc test and by unpaired Student's t-test for comparison between groups as appropriate. Differences were considered significant at $p<0.05$. Data are expressed as mean $\pm \mathrm{SD}$. Delta value percent $(\Delta \%)$ is calculated as [(L-T4 final dose/ L-T4 dose before pregnancy x100)-100]. Analysis was performed using SPSS (version 14.0, SPSS Inc., Chicago, IL, USA).

\section{RESULTS}

Of the eighty six patients, $\mathrm{L}-\mathrm{T}_{4}$ doses were increased one or more times in 50 patients $(58.13 \%)$, decreased one or more times in 3 patients $(3.49 \%)$, increased and then decreased in $4(4.65 \%)$ and not modified in $29(33.72 \%)$ patients due to thyroid sufficiency. In the 50 patients who needed to increase $\mathrm{L}-\mathrm{T}_{4}$, the mean dosage increment was $17.46 \pm 30.8 \mu \mathrm{g}$ day $^{1}$ at the first evaluation during pregnancy. Among patients who increased $\mathrm{L}_{-} \mathrm{T}_{4}$ dose, $13(26 \%)$ reached a definitive therapeutic dosage within the 12th week of gestation, 12 (24\%) within the 20th and $25(50 \%)$ within the 31 st. Among the three groups of patients who reached a definitive therapeutic dosage within the 12th, 20th and 31st week of gestation, there was no significant difference between the groups when comparing starting doses, final doses of ${\mathrm{L}-\mathrm{T}_{4}}_{4}$ expressed as $\mu \mathrm{g} / \mathrm{day}$ and $\Delta \%$ of $\mathrm{L}^{-\mathrm{T}_{4}}$ doses. However, statistically significant difference was found between the final doses among the groups when expressed as $\mu \mathrm{g} / \mathrm{kg}$ day (Table 1). This may be due to progressive body weight increase during pregnancy, since there is an observed increased demand for thyroxine which is reflected in the Table 1. A study by Verga et al. (2009) showed that timing of L-T modification was independent of the body weight increment, the initial dosage ( $\mu \mathrm{g} /$ day and $\mu \mathrm{g} / \mathrm{kg}$ day), the L- $\mathrm{T}_{4}$ increases and the aetiology of hypothyroidism.

By dividing the patients on the basis of aetiology of hypothyroidism, initial and final L-T4 doses (either as 76 
Am. J. Infect. Dis., 7 (3): 75-79, 2011

Table 1:Initial and final $\mathrm{L}-\mathrm{T}_{4}$ doses and delta $(\Delta \%)$ in 50 patients already treated before pregnancy who increased the substitutive therapy. Patients divided in three groups depending on the week of gestation at which the definitive dose was reached

\begin{tabular}{|c|c|c|c|c|}
\hline & \multicolumn{3}{|c|}{ Week of gestation (median) } & \multirow[b]{2}{*}{$\mathrm{P}$ value (ANOVA) } \\
\hline & 12 & 20 & 31 & \\
\hline Number of patients & 13 & 12 & 25 & \\
\hline $\mathrm{L}-\mathrm{T}_{4}$ doses before pregnancy ( $\mu \mathrm{g} /$ day) & $80.77 \pm 30.87(25-125)$ & $102.38 \pm 28.83(50-150)$ & $92.74 \pm 32.67(37.5-150)$ & NS \\
\hline $\mathrm{L}-\mathrm{T}_{4}$ doses at the end of pregnancy $(\mu \mathrm{g} /$ day $)$ & $111.67 \pm 26.26(75-150)$ & $130.36 \pm 26.56(75-175)$ & $140.14 \pm 44.33(75-200)$ & NS \\
\hline$\Delta$ of $\mathrm{L}^{-\mathrm{T}_{4}}$ absolute doses $(\mu \mathrm{g} /$ day $)(\%)^{\neq}$ & $59.05 \pm 66.9(12.5-200)$ & $30.79 \pm 18.95(9.52-75)$ & $59.45 \pm 46.58(9.53-166.67)$ & NS \\
\hline $\mathrm{L}-\mathrm{T}_{4}$ doses before pregnancy ( $\mu \mathrm{g} / \mathrm{kg}$ day) & $1.25 \pm 0.49(0.34-1.82)$ & $1.6 \pm 0.53(0.81-2.48)$ & $1.6 \pm 0.54(0.42-2.69)$ & NS \\
\hline $\mathrm{L}_{-} \mathrm{T}_{4}$ doses at the end of pregnancy $(\mu \mathrm{g} / \mathrm{kg}$ day) & $1.58 \pm 0.49(0.95-2.68)$ & $1.79 \pm 0.49(1.06-2.79)$ & $2.14 \pm 0.72(0.79-3.88)$ & $<0.05$ \\
\hline
\end{tabular}

Table 2: Initial and final dose and FT4 levels in patients with subclinical $(\mathrm{SCH})$ and overt $(\mathrm{OH})$ hypothyroidism already treated before pregnancy who increased the substitutive therapy

\begin{tabular}{|c|c|c|c|}
\hline & $\mathrm{SCH}$ & $\mathrm{OH}$ & P-value \\
\hline Number of patients & 18 & 32 & \\
\hline $\mathrm{L}_{-} \mathrm{T}_{4}$ doses before pregnancy $(\mu \mathrm{g} /$ day $)$ & $83.14 \pm 30.78(25-125)$ & $96.89 \pm 31.55(50-150)$ & NS \\
\hline $\mathrm{L}-\mathrm{T}_{4}$ doses at the end of pregnancy ( $\mu \mathrm{g} /$ day) & $130.95 \pm 42.04(75-200)$ & $130.08 \pm 35.96(75-200)$ & NS \\
\hline$\Delta$ of $\mathrm{L}-\mathrm{T}_{4}$ absolute doses ( $\mu \mathrm{g} /$ day $)(\%)^{¥}$ & $74.08 \pm 62.36(12.5-200)$ & $40.31 \pm 34.97(9.52-150)$ & $<0.05$ \\
\hline L-T $\mathrm{T}_{4}$ doses before pregnancy ( $\mu \mathrm{g} / \mathrm{kg}$ day) & $1.43 \pm 0.54(0.34-2.33)$ & $1.49 \pm 0.57(0.46-3.1)$ & $\mathrm{NS}$ \\
\hline $\mathrm{L}^{-} \mathrm{T}_{4}$ doses at the end of pregnancy ( $\mu \mathrm{g} / \mathrm{kg}$ day) & $1.78 \pm 0.75(0.78-3.88)$ & $1.6 \pm 0.65(0.41-3.36)$ & NS \\
\hline Serum $\mathrm{FT}_{4}$ levels at the first evaluation $(\mathrm{pmol} / \mathrm{L})$ & $15.71 \pm 2.55(11.28-20.78)$ & $16.37 \pm 4.28(8.23-25.15)$ & NS \\
\hline Serum $\mathrm{FT}_{4}$ levels at the end of pregnancy $(\mathrm{pmol} / \mathrm{L})$ & $14.86 \pm 3.28(11.13-23.5)$ & $15.26 \pm 2.3(9.99-19.53)$ & NS \\
\hline
\end{tabular}

Data are expressed as mean \pm SD and (range) $¥ \Delta \%=[(\mathrm{L}-\mathrm{T} 4$ final dose/L-T4 dose before pregnancy $* 100)-100]$

The $\Delta \%$ of absolute doses were significantly different in the two groups of patients being $+74.08 \%$ in Subclinical Hypothyroid $(\mathrm{SCH})$ and $+40.31 \%$ in overt hypothyroid $(\mathrm{OH})$ as compared to baseline dose. The increment was higher in $\mathrm{SCH}$ than $\mathrm{OH}$ group (Table 2).

\section{DISCUSSION}

The mother is the main source of thyroxine for the fetus during the first trimester and the predominant source during the first half of gestation, a time that the key structures in the fetal brain develop (Calvo et al., 2002). Additionally the requirement of maternal Thyroxine $\left(\mathrm{T}_{4}\right)$ increases during pregnancy (Glinoer, 1997). It is, therefore, important that maternal deficits in thyroxine which may develop in women with hypothyroidism during pregnancy should be corrected as early as possible. It was observed that in $34.9 \%$ of patients on $\mathrm{L}-\mathrm{T}_{4}$ substitution before pregnancy, serum TSH values were abnormal when first tested and they had increased chances of fetal loss if not treated timely. Most pregnant patients (50-85\%) will have to increase the L- $\mathrm{T}_{4}$ dose (Abalovich et al., 2002; Alexander et al., 2004; Kaplan, 1992; McDougall and Maclin, 1995), though a few studies found that only the minority (21$44 \%$ ) needed to do so (Chopra and Babaer, 2003; Kothari and Girling, 2008).

In $58.13 \%$ of patients already adequately treated before conception, $\mathrm{L}-\mathrm{T}_{4}$ dosage was increased during the course of pregnancy, thus confirming that strict evaluation of thyroid function during pregnancy is crucial (Alexander et al., 2004). It is worth noting that a consistent number of patients reached the definitive dosage only at the second and third trimester of pregnancy due to progressive hormonal change. These findings are in line with Verga et al. (2009) who found that, of those patients whose dose was increased, only $6 \%$ normalized the levels in the first trimester and almost half (46.2\%) achieved normal levels only during the third trimester after the key period for the maternal $\mathrm{T}_{4}$ input had already passed.

According to the week of gestation in which patients reached adequate treatment, it is worth noting that $\mathrm{L}^{-\mathrm{T}_{4}}$ final dosage was lower in patients who reached a definitive therapeutic dosage within the 12 and 20th than that of patients who reached a definitive therapeutic dosage within the 31st week, despite the body weight increase. Several possible explanations can be put forth for an increased requirement at different times during gestation. In early pregnancy, thyroxinebinding globulin increases and consequently more thyroid hormones are required. Later with placental growth, there is increased $T_{4}$ metabolism to its inactive metabolite reverse- triiodothyronine $\left(\mathrm{rT}_{3}\right)$ by high levels of placental de-iodinase type III (Glinoer, 1997). In addition, there is some placental transfer of maternal $\mathrm{T}_{4}$ and a different distribution of thyroid hormones in the fetal/ placental unit (Zigman et al., 2003). Due to this it is recommended not only to increase treatment as soon as pregnancy is confirmed, but also to carefully followup patients every month until term.

Initial and final $\mathrm{L}_{-} \mathrm{T}_{4}$ doses were almost similar in both $\mathrm{SCH}$ and $\mathrm{OH}$ group. Although, patients with $\mathrm{SCH}$ showed the high increment of $\mathrm{L}-\mathrm{T}_{4}$ dosage, with a mean 
dosage increment of $74.08 \%$ over the preconception replacement dosage when percent increase of $\mathrm{L}_{-} \mathrm{T}_{4}$ was expressed as $\Delta \%$ of absolute dose. Almost $50 \%$ of patients with $\mathrm{SCH}$ required higher dosage increments, though they appeared to be adequately treated before pregnancy. The present data supports the recent Endocrine Society guidelines for the management of thyroid dysfunction during pregnancy, in which ${\mathrm{L}-\mathrm{T}_{4}}_{4}$ treatment was recommended in $\mathrm{SCH}$ pregnant patients, given that the potential benefits out weighted the potential risks (Abalovich et al., 2007).

\section{CONCLUSION}

In summary, it is important to achieve ideal serum TSH and $\mathrm{FT}_{4}$ concentrations in women with hypothyroidism during pregnancy, especially during the first trimester. To best achieve this goal, thyroid status on $\mathrm{L}-\mathrm{T}_{4}$ needs to be optimized even before the patient becomes pregnant. Therefore, most of them will require $\mathrm{L}_{-} \mathrm{T}_{4}$ dosage increment during gestation, thus reducing the risk of inadequate treatment. The aetiology of hypothyroidism may influence the adjustment of $\mathrm{L}-\mathrm{T}_{4}$ therapy. The close follow-up and correction of hypothyroidism during pregnancy is essential for the gestation continuity and the fetal health. Serum TSH and $\mathrm{FT}_{4}$ measurements are mandatory in all pregnant women to prevent risks of adverse maternal and neonatal outcomes.

\section{ACKNOWLEDGEMENT}

The researchers express gratitude to Indian Council of Medical Research (ICMR) for providing the financial assistance and Institute of Nuclear Medicine and Allied Sciences (INMAS) for providing all the facilities to carry out this research work.

\section{REFERENCES}

Abalovich, M., N. Amino, L.A. Barbour, R.H. Cobin and L.J. De Groot et al., 2007. Management of thyroid dysfunction during pregnancy and postpartum: An endocrine society clinical practice guideline. J. Clin. Endocrinol. Meatb., 92: s1-s47. PMID: 17948378.

Abalovich, M., S. Gutierrez, G. Alacaraz, G. Maccallini and A. Garcia et al., 2002. Overt and subclinical hypothyroidism complicating pregnancy. Thyroid, 12: 63-68. PMID: 11838732
Alexander, E.K., E. Marqusee, J. Lawerence, P. Jarolim and G.A. Fischer et al., 2004. Timing and magnitude of increases in levothyroxine requirements during pregnancy in women with hypothyroidism. N. Engl. J. Med., 351: 241-249. PMID: 15254282

Allan, W.C., J.E. Haddow, G.E. Palamoki, J.R. Williams and M.L. Mitchell et al., 2000. Maternal thyroid deficiency and pregnancy complications: Implications for population screening. J. Med. Screen, 7: 127-130. PMID: 11126160

Burrow, G.N., D.A. Fisher and P.R. Larsen, 1994. Maternal and fetal thyroid function. N. Engl. J. Med., 20: 1072-1078. PMID: 8090169

Calvo, R., E. Janiaux, B. Gulbis, M. Asuncion and C. Gervy et al., 2002. Fetal tissues are exposed to biologically relevant free thyroxine concentrations during early phases of development. J Clin. Endocrinol. Metab., 87: 1768-1777. PMID: 11932315.

Casey, B.M., J.S. Dashe, C.E. Well, D.D. McIntire and W. Byrd et al., 2005. Subclinical hypothyroidism and pregnancy outcomes. Obstet. Gynecol., 105: 239-245. PMID: 15684146

Chopra, I.J. and K. Babaer, 2003. Treatment of primary hypothyroidism during pregnancy: Is there an increase in thyroxine dose requirement in pregnancy? Metab. Clin. Exp., 52: 122-128. PMID: 12524672

Davis, L.E., K.J. Leveno and F.G. Cunningham, 1988. Hypothyroidism complicating pregnancy. Obstet Gynecol., 72: 108-112. PMID: 3380497

Glinoer, D., 1997. The regulation of thyroid function in pregnancy: Pathways of endocrine adaptation from physiology to pathology. Endocr. Rev., 18: 404433. PMID: 9183570.

Idris, I., R. Srinivasan, A. Simm and R.C. Page, 2005. Maternal hypothyroidism in early and late gestation: Effects on neonatal and obstetric outcome. Clin. Endocrinol., 63: 560-565. PMID: 16268809.

Kaplan, M.M., 1992. Monitoring thyroxine treatment during pregnancy. Thyroid, 2: 147-152. PMID: 1525583

Kothari, A. and J. Girling, 2008. Hypothyroidism in pregnancy: pre-pregnancy thyroid status influences gestational thyroxine requirements. Br J. Obstset. Gynaecol., 115: 1704-1708. PMID: 18947343.

Leung, A.S., L.K. Millar, P.P. Koonings, M. Montoro and J.H. Mestman, 1993. Perinatal outcome in hypothyroid pregnancies. Obstet. Gynecol., 81: 349-353. PMID: 8437784 
McDougall, I.R. and N. Maclin, 1995. Hypothyroid women need more thyroxine when pregnant. J. Fam Pract., 41: 238-240. PMID: 7650501

Pop, V.J., E.P. Brouwers, H.L. Vader, T. Vulsma and A.L. Van Baar et al., 2003. Maternal hypothyroxinaemia during early pregnancy and subsequent child development: A 3-year follow-up study. Clin. Endocrinol., 59: 282-288. PMID: 12919150
Verga, U., S. Bergamaschi, D. CorteLazzi, S. Ronzoni and A.M. Marconi et al., 2009. Adjustment of LT4 substitutive therapy in pregnant women with subclinical, overt or post-ablative hypothyroidism. Clin. Endocrinol., 70: 798-802. PMID: 18771569.

Zigman, J.M., S.E. Cohen and J.R. Garber, 2003. Impact of thyroxine-binding globulin on thyroid hormone economy during pregnancy. Thyroid, 13: 1169-1175. PMID: 14751039 